\title{
Influences of Feed and Cross Angle on Inside Bore and Lamination Defects in Rotary Piercing for Materials with Poor Hot Workability
}

\author{
Chihiro HAYASHI and Tomio YAMAKAWA \\ Corporate Research and Development Laboratories, Sumitomo Metal Industries, Ltd., Fuso-cho, Amagasaki, Hyogo-ken, 660 \\ Japan.
}

(Received on July 15, 1996; accepted in final form on November 12, 1996)

\begin{abstract}
A cone-type piercing mill has been developed for piercing the materials with poor hot workability. This piercing mill is called "the super piercing mill" in Europe and America. This mill has cone-type main rolls supported at both ends with their roll axes inclined and crossed so as to enable piercing at a high feed and cross angle. This configuration is based on the following principles: by rendering the material more ductile than its mother material in front of the plug, any possible cause of the initiation of inside bore defects can be eliminated; and, at the same time, by releasing the redundant shear stress field during piercing process, it is possible to eliminate any possible cause of the propagation of inside bore defects. In order to ensure the best performance of the rotary piercing, disc rolls have been adopted instead of plate guide shoes. Piercing experiments were carried out using test materials with poor hot workability, such as continuously cast round billet, stainless steel, high alloy steel and $\mathrm{Pb}-\mathrm{S}$ free cutting steel, with the feed and cross angle changed in various ways. The influences of the feed and cross angle on the inside bore and lamination defects were studied in detail. Furthermore, piercing experiments under high feed and cross angles were carried out with titanium, titanium alloy, zirconium alloy, nickel and nickel alloy in order to confirm the effects of such a high-angles piercing.
\end{abstract}

KEY WORDS: rotary piercing process; materials with poor hot workability; continuously cast round billet; stainless steel; high alloy steel; free cutting steel; non ferrous metal; micro bore defects; inside bore defects; lamination defects.

\section{Introduction}

The Mannesmann piercing of any forged carbon steel material poses no problem regarding the inside bore quality. However, when the Mannesmann piercing is carried out with a continuously cast round billet, the center porosities of the round billet will develop into micro bore defects because of a redundant shear stress field during piercing process. The micro bore defects are very small in size i.e., $1-3 \mathrm{~mm}$, so that they may easily escape visual inspection. The presence of such micro defects can be recognized only by the dye check (colour check).

The hot workability of stainless steel, even if it is forged steel, is far poorer than that of carbon steel. Therefore, when such a material is served for the piercing process, voids may occur from any inclusions and/or segregations in front of the plug. Such voids will develop into noticeable inside bore defects as they are under a redundant shear stress field during piercing operation. This feature is more distinctive in continuously cast round billets of stainless steel.

The hot workability of high alloy steel is far worse as compared with that of stainless steel, and not only induces noticeable inside bore defects but also causes shearing of a central portion of the wall, namely, lamination defects.

Therefore, these stainless and high alloy steel tubes have been manufactured through the Ugine-Sejournet extrusion process.

Free cutting steel also poses a serious problem, even in the case of forged steel; its hot workability is as poor as those of stainless and high alloy steel; and it also has distinctive inside bore defects.

An ideal piercing mill for these materials with a poor hot workability has been developed which is specifically known as the super piercing mill. As illustrated in Fig. 1, this piercing mill has cone-type main rolls supported at both ends with their roll axes inclined and, at the same time, crossed so as to enable piercing at a high feed and cross angle. In order to ensure the best performance of rotary piercing, the disc rolls have been adopted instead of plate guide shoes. The principles underlying this arrangement are as follows. By rendering the billet material more ductile than its mother material in front of the plug, any possible cause of the initiation of inside bore defects can be eliminated and, by releasing the redundant shear stress field during piercing process, it is possible to eliminate any possible cause of the propagation of inside bore defects.

Piercing experiments were carried out under the various feed and cross angles using above materials with 


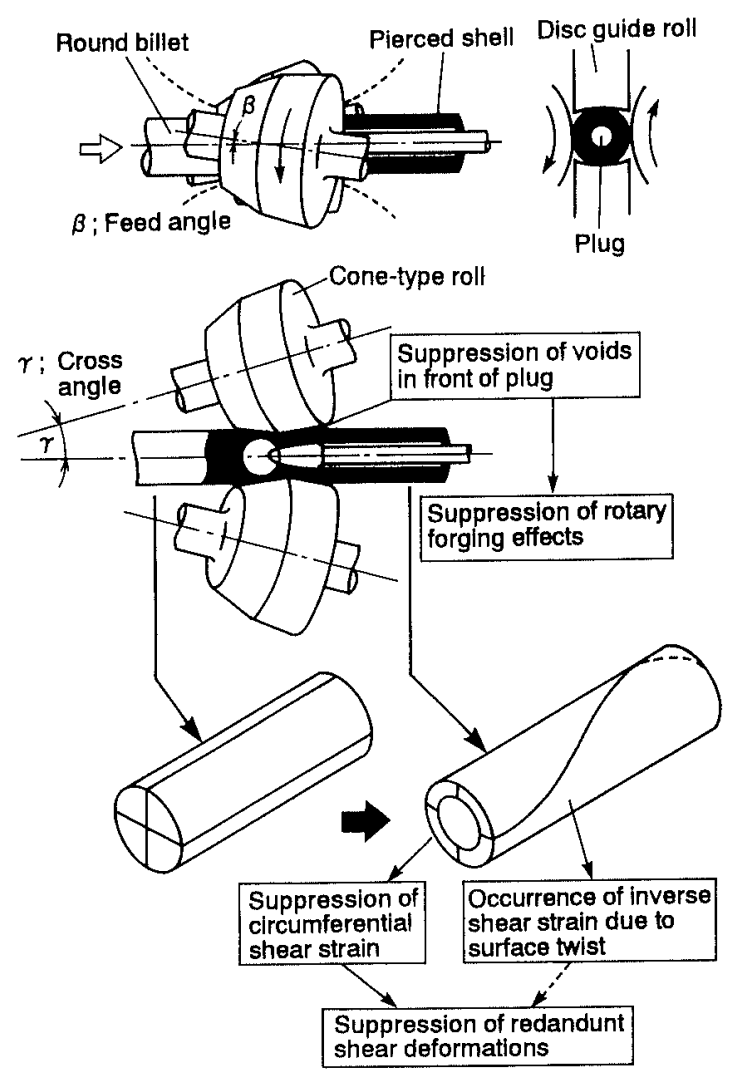

Fig. 1. Principles and features of the cone-type piercing mill (the super piercing mill).

poor workability. The influences of the feed and cross angle on the inside bore and lamination defects were studied in detail by using a model piercing mill for experimental use.

Furthermore, piercing experiments under high feed and cross angles were also carried out with titanium, titanium alloy, zirconium alloy, nickel and nickel alloy in order to confirm the effect of such a high-angles piercing. The general views of the model piercing mill for experimental use are shown in Fig. 2.

2. Influences of the Feed and Cross Angle on the Micro Bore Defects in the Shell Pierced from Continuously Cast Round Billets

\subsection{Experimental Procedure}

The center porosities in the continuously cast round billets tend to develop into the micro bore defects under the influence of a shear stress field during piercing operation. Billets of a $70 \phi$ diameter were used as test specimens which cut out from the center portion of the continuously cast round billets, which had a diameter of $282 \phi$, of $0.2 \mathrm{C}(0.2 \% \mathrm{C}), 0.5 \mathrm{C}$ and $0.3 \mathrm{C}-1.3 \mathrm{Mn}$ steel. With these specimens, piercing experiments were carried out by changing the feed and cross angle and also the electromagnetic stirring conditions. The influences of the feed and cross angle and the electromagnetic stirring condition on the number of micro bore defects per unit length were studied in detail. In this experiment, the piercing ratio (piercing elongation) was set within the range from 1.8 to 3.1 , and the expansion ratio from 1.00 to 1.08 . The heating temperature was fixed at $1220^{\circ} \mathrm{C}$.

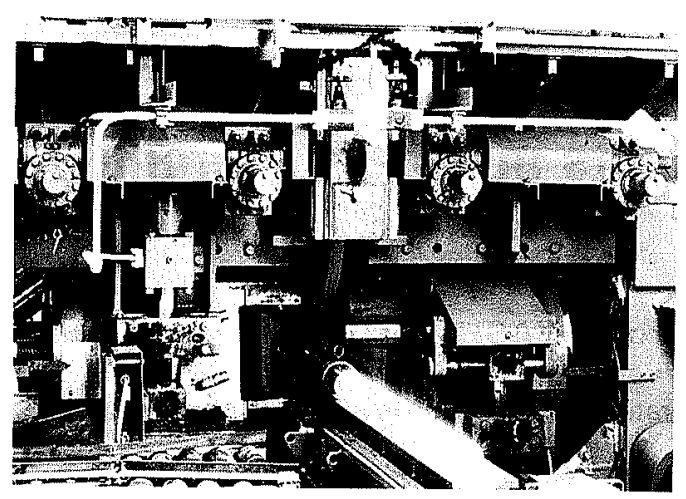

(a) Entry side view

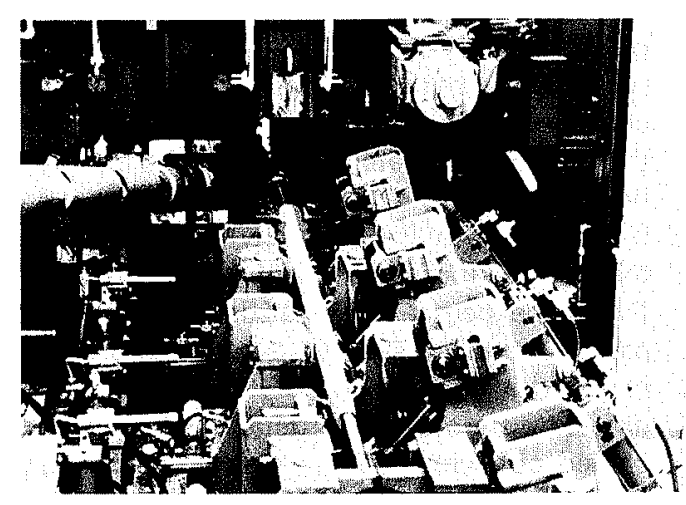

(b) Exit side view

Fig. 2. General views of the model piercing mill for experimental use

\subsection{Experimental Results and Discussion}

The influences of the feed and cross angle and the electromagnetic stirring condition on the number of micro bore defects per unit length are shown in Figs. 3 and 4 . The results are summarized as follows.

(1) The larger the feed and cross angle are, the more remarkable is the decrease in the number of micro bore defects. On the other hand, the influence of the piercing ratio is not so clear.

(2) Piercing at $\beta=16^{\circ}$ and $\gamma=15^{\circ}$, results in a sharp decrease in the number of the micro bore defects to several percent or a fewer number of such defects occurring in the case of piercing at $\beta=8^{\circ}$ and $\gamma=0^{\circ}$.

(3) The application of the electromagnetic stirring in the piercing process at $\beta=16^{\circ}$ and $\gamma=15^{\circ}$, results in a drastic decrease in the number of the micro bore defects to almost none.

(4) Above mentioned results correspond to the influences of the feed and cross angle on the redundant shear deformations. The larger the feed and cross angle are, the smaller is the circumferential shear strain $\gamma_{r \theta}$. It is very clear that the shear stress fields is a cause of the propagation of micro bore defects.

\section{Influences of the Feed and Cross Angle on the Inside} Bore Defects in Stainless Steel

\subsection{Experimental Procedure}

Piercing experiments were carried out by using four 


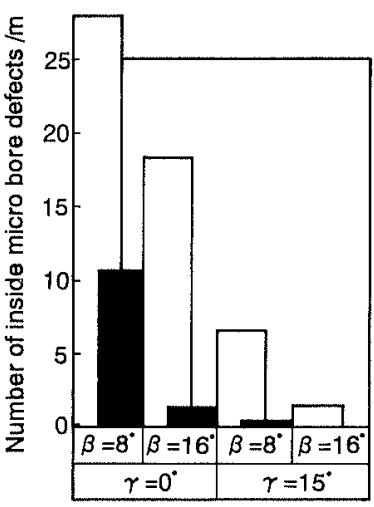

(1) $\mathrm{H} 2 \mathrm{O}(0.2 \mathrm{C})$

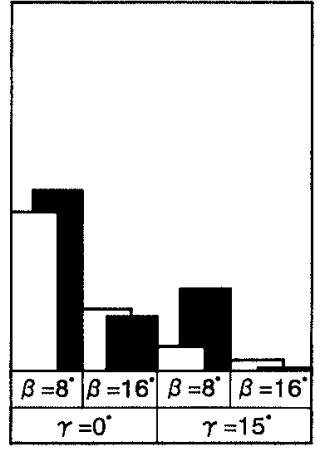

(2) $\mathrm{H} 50(0.5 \mathrm{C})$

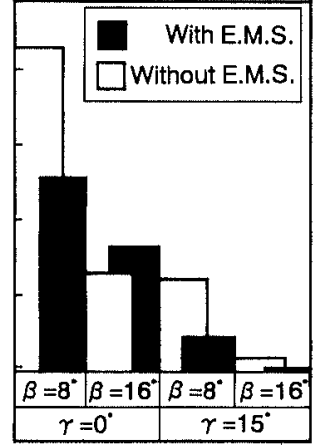

(3) HS3(0.3C-1.3Mn)

Fig. 3. Influences of the feed and cross angle and the electromagnetic stirring on the number of inside micro bore defects per unit length in the shell pierced from continuously cast round billet.

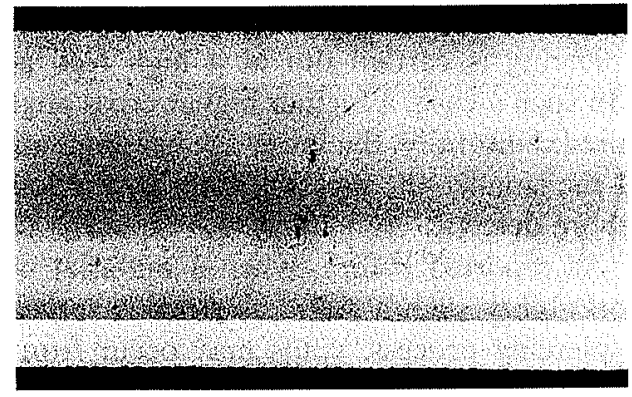

(a) Cross angle $=0^{\circ}$, Feed angle $=8^{\circ}$

Piercing ratio $=2.0$, Heat temperature $=1220^{\circ} \mathrm{C}$

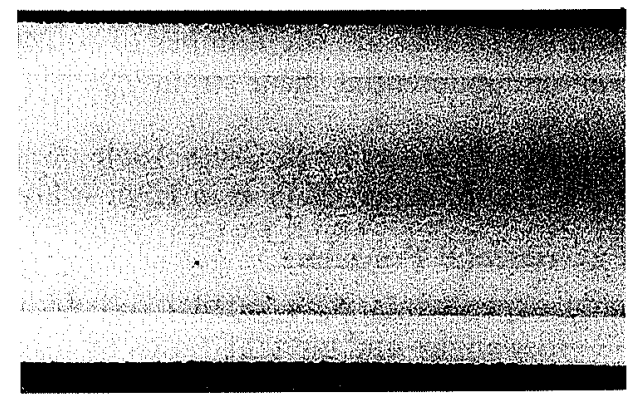

(b) Cross angle $=15^{\circ}$, Feed angle $=16^{\circ}$

Piercing ratio $=2.0$, Heat temperature $=1220^{\circ} \mathrm{C}$

Fig. 4. Influences of the feed and cross angle on the inside micro bore defects in the shell pierced from C.C. round billet. (H50:0.5C)

typical kinds of stainless steels, i.e., $18 \mathrm{Cr}-8 \mathrm{Ni}-2.5 \mathrm{Mo}$, $18 \mathrm{Cr}-8 \mathrm{Ni}-\mathrm{Cb}, 25 \mathrm{Cr}-7 \mathrm{Ni}-3 \mathrm{Mo}-\mathrm{W}-\mathrm{Cu}-\mathrm{N}$ and $25 \mathrm{Cr}-$ $20 \mathrm{Ni}$, in the form of forged and continuously cast round billets at various feed and cross angles. The influences of the feed and cross angle on the inside bore defects were studied in detail.

Billets of a $60 \phi$ diameter were used as test specimens. The piercing ratio was set within the range from 2.0 to 3.5 , the heating temperature from $1180^{\circ}$ to $1270^{\circ} \mathrm{C}$, and the expansion ratio from 1.02 to 1.08 .

Furthermore, with the forged stainless steel billets of $18 \mathrm{Cr}-8 \mathrm{Ni}-\mathrm{Cb}$, piercing experiments were carried out at the various heating temperatures and piercing ratios (piercing elongations). The influences of the heating temperature and piercing ratio on the inside bore defects
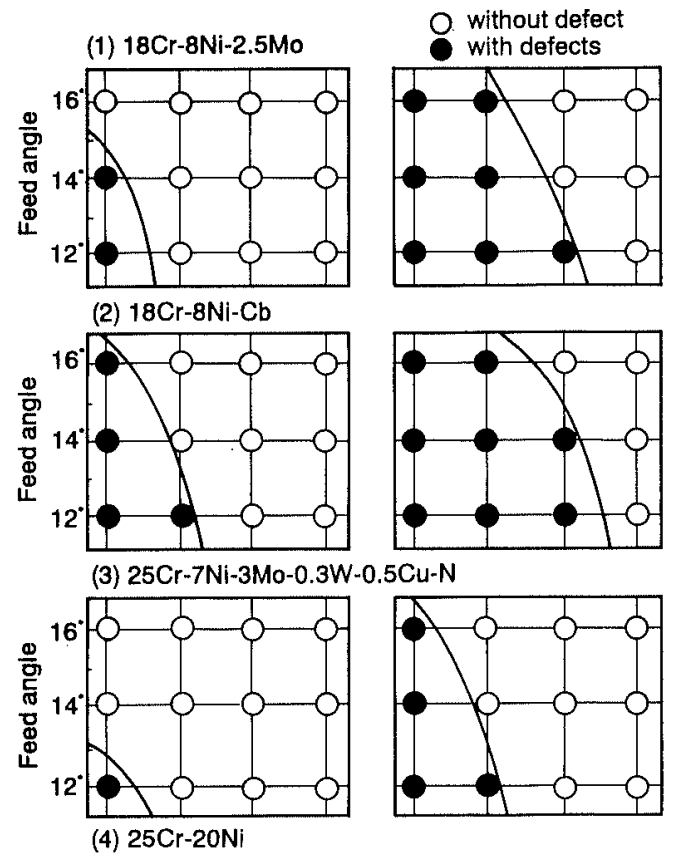

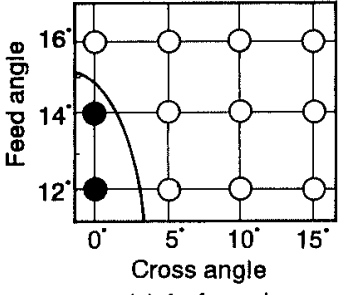

(a) As forged

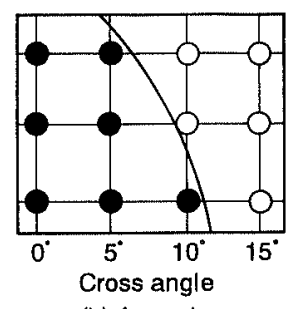

(b) As cast
Fig. 5. Influences of the feed and cross angle on the inside bore defects in stainless steel

were examined in detail.

\subsection{Experimental Results and Discussion}

The influences of the feed and cross angle on the inside bore defects in stainless steels are shown in Figs. 5 and 6, and those of the heating temperature and piercing ratio in Fig. 7. The results are summarized as follows.

(1) The influences of the feed and cross angle on the inside bore defects in stainless steel are obvious. In either case of the forged or the continuously cast round billets, the larger the feed and cross angle are, the less are the inside bore defects.

(2) In the case of the forged billets, some difficulty 


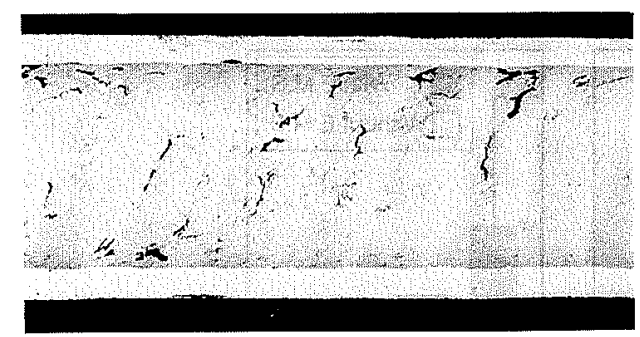

(a) Cross angle $=0^{\circ}$, Feed angle $=12^{\circ}$ Piercing ratio $=2.5$, Heat temperature $=1220^{\circ} \mathrm{C}$

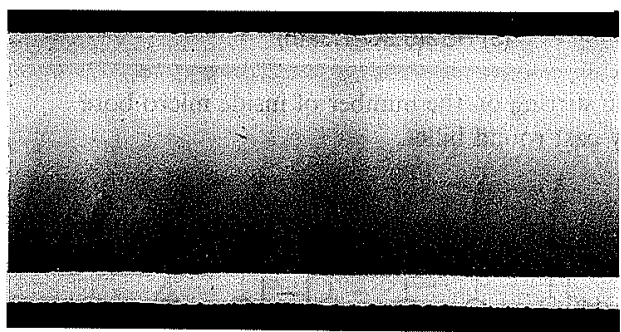

(b) Cross angle $=15^{\circ}$, Feed angle $=16^{\circ}$ Piercing ratio $=2.5$, Heat temperature $=1220^{\circ} \mathrm{C}$

Fig. 6. Influences of the feed and cross angle on the inside bore defects in stainless steel. $(18 \mathrm{Cr}-8 \mathrm{Ni}-\mathrm{Cb})$
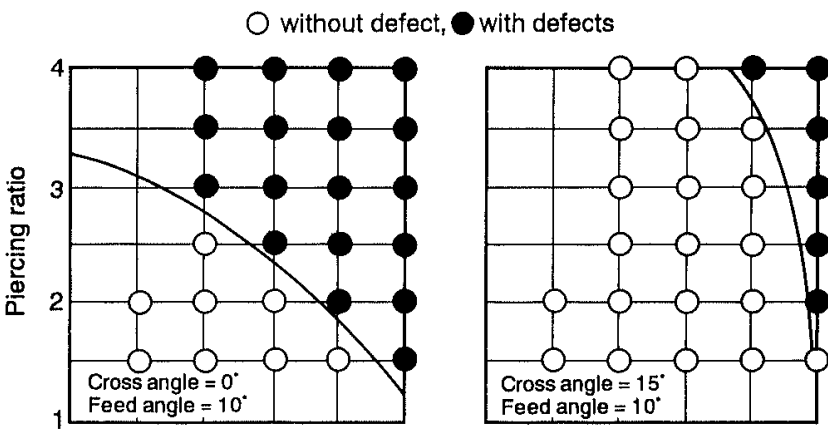

(a) Influences of heating temperature, piercing ratio and cross angle.
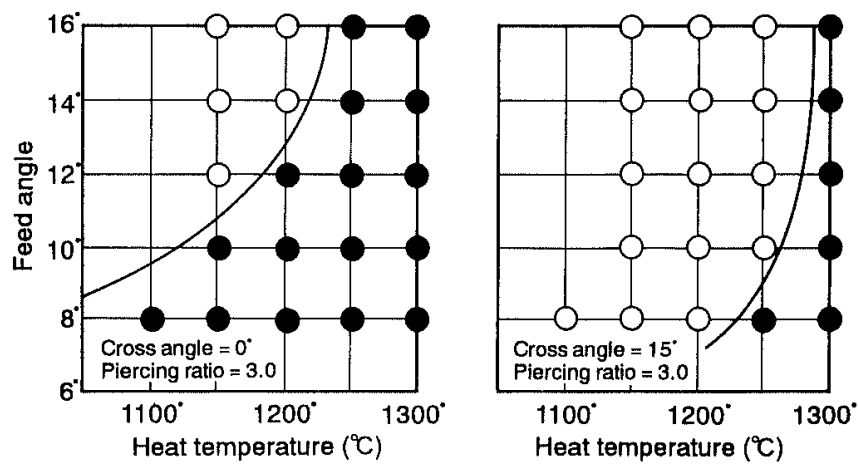

(b) Influences of heating temperature, feed and cross angle.

Fig. 7. Influences of the heating temperature and piercing ratio on the inside bore defects in stainless steel. $(18 \mathrm{Cr}-8 \mathrm{Ni}-\mathrm{Cb})$

may be encountered in piercing the $\mathrm{Cb}$-added stainless steel. In this case, piercing at a high feed and low cross angle provides good inside bore quality. On the other hand, if piercing is carried out at a low feed and cross angle, the inside bore defects occur inevitably.

(3) In the case of the continuously cast round billets which have poorer hot workability than the forged ones, lamination defects are likely to occur in a central portion of the wall in addition to inside bore defects. In the case of such billets, however, the influences of the feed and cross angle are more pronounced. Irrespective of the billet materials, a satisfactory inside bore quality free from bore defects, can be obtained only at a high feed and cross angle operation.

(4) The results of the detailed piercing experiments with the forged billets of $18 \mathrm{Cr}-8 \mathrm{Ni}-\mathrm{Cb}$ show that heat generation due to piercing operation deteriorates the hot workability of the steel and the inside bore quality. A suitable heating temperature should be selected, considering the heat generation due to piercing operation.

(5) Heat generation due to working becomes greater as the piercing ratio becomes larger. In the case of a large piercing ratio, if an incorrect heating temperature is selected, the inside bore defects are likely to occur even when piercing is carried out at a high feed and cross angle. In such a case, a further higher cross angle setting is required. Naturally, the lower the heating temperature is, and the smaller the piercing ratio is, the less are the inside bore defects.

(6) As reported before, when a material with poor hot workability such a stainless steel, is served for the rotary piercing process, voids may occur from any inclusions and/or segregations in front of the plug. And then, such voids will develop into noticeable inside bore defects as they are under a redundant shear stress field during piercing operation. The larger the feed and cross angle are, the smaller are the number of rotary forging times and circumferential shear strain $\gamma_{r \theta}$.

\section{Influences of the Feed and Cross Angle on the Inside Bore and Lamination Defects in High Alloy Steel}

\subsection{Experimental Procedure}

Piercing experiments were carried out with various feed and cross angles and piercing ratios by using forged billets of four typical kinds of high alloy steels, as test specimens, i.e., $25 \mathrm{Cr}-35 \mathrm{Ni}-3 \mathrm{Mo}, 30 \mathrm{Cr}-40 \mathrm{Ni}-3 \mathrm{Mo}$, $25 \mathrm{Cr}-50 \mathrm{Ni}-6 \mathrm{Mo}$ and $20 \mathrm{Cr}-50 \mathrm{Ni}-9 \mathrm{Mo}$, selected from $\mathrm{Cr}-, \mathrm{Ni}-$, and Mo-based high alloy steels. The influences of the feed and cross angle and piercing ratio on the inside bore and lamination defects with respect to $\mathrm{Cr}$-, $\mathrm{Ni}-$, and Mo-based high alloy steels were examined in detail. Billets of a $60 \phi$ diameter were used as test specimens. The piercing ratio was set within the range from 1.9 to 3.5 , and the heating temperature from $1200^{\circ}$ to $1270^{\circ} \mathrm{C}$. The expansion ratio was fixed at 1.05 . Furthermore, piercing experiments were also conducted at various heating temperatures and piercing ratios by using the forged billets of $25 \mathrm{Cr}-50 \mathrm{Ni}-6 \mathrm{Mo}$ steel as test specimens. The influences of the heating temperature and piercing ratio on the inside bore and lamination defects were closely studied.

\subsection{Experimental Results and Discussion}

The influences of the feed and cross angle and piercing ratio on the inside bore and lamination defects in high alloy steel are shown in Figs. 8 and 9, and those of the heating temperature and piercing ratio in Fig. 10. The 


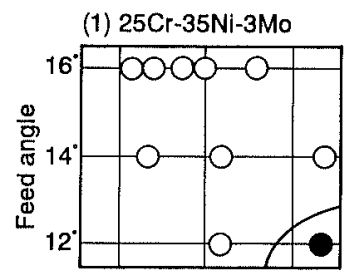

O without defect, 9 with defects
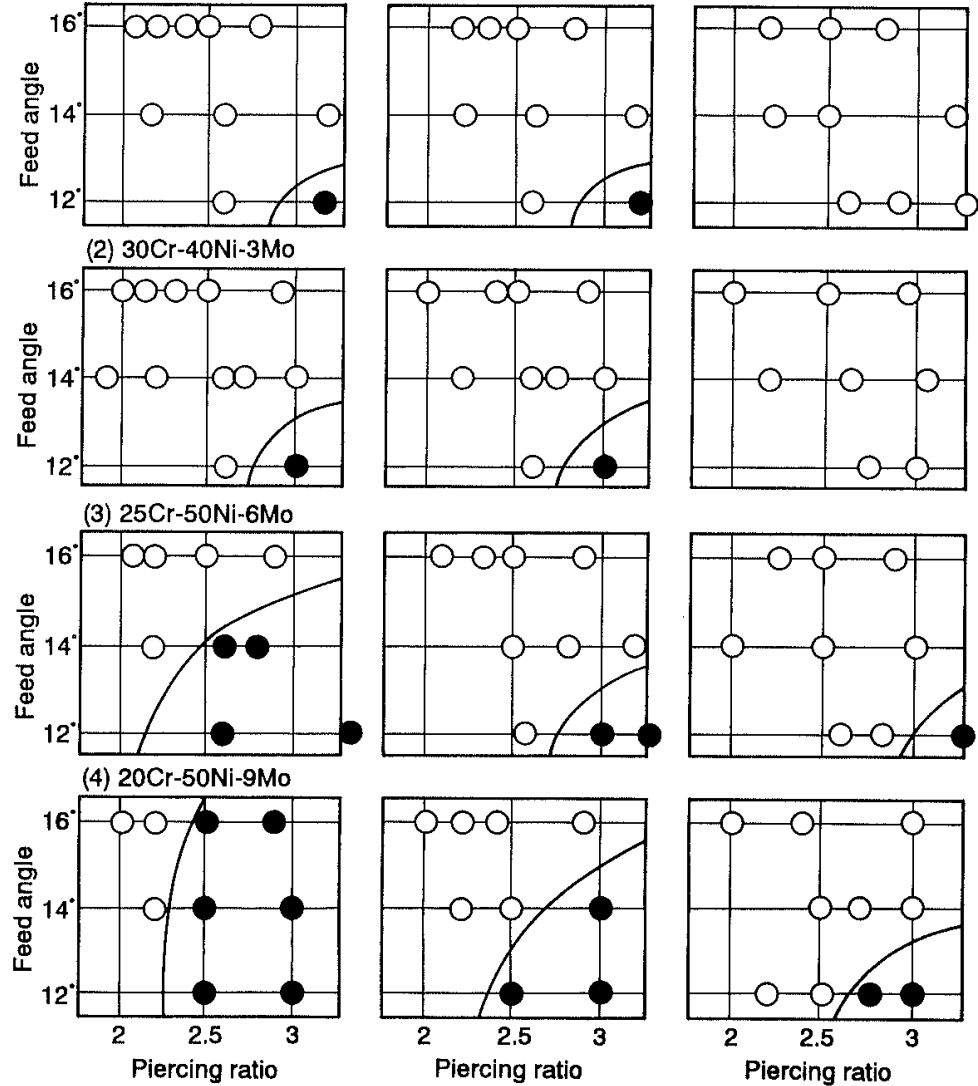

(a) Cross angle $=10$

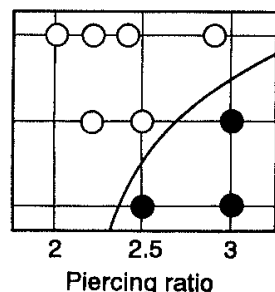

(b) Cross angle $=15$

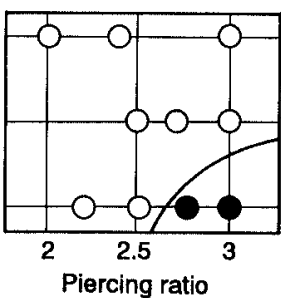

(c) Cross angle $=20^{\circ}$

Fig. 8. Influences of the piercing ratio, feed and cross angle on the inside bore and lamination defects in high alloy steel.

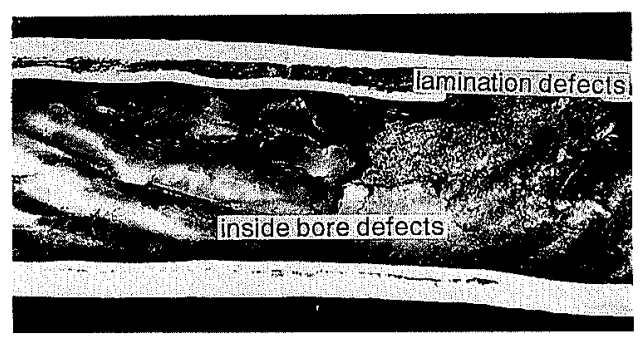

(a) Cross angle $=0^{\circ}$, Feed angle $=12^{\circ}$

Piercing ratio $=2.5$, Heat temperature $=1240^{\circ} \mathrm{C}$

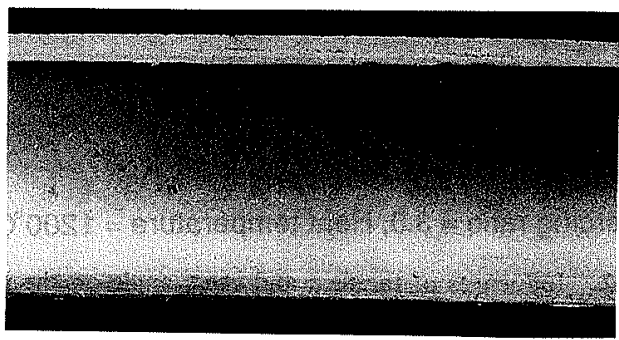

(b) Cross angle $=20^{\circ}$, Feed angle $=16^{\circ}$

Piercing ratio $=2.5$, Heat temperature $=1240^{\circ} \mathrm{C}$

Fig. 9. Influences of the feed and cross angle on the inside bore and lamination defects in high alloy steel. (20Cr-50Ni-9Mo)

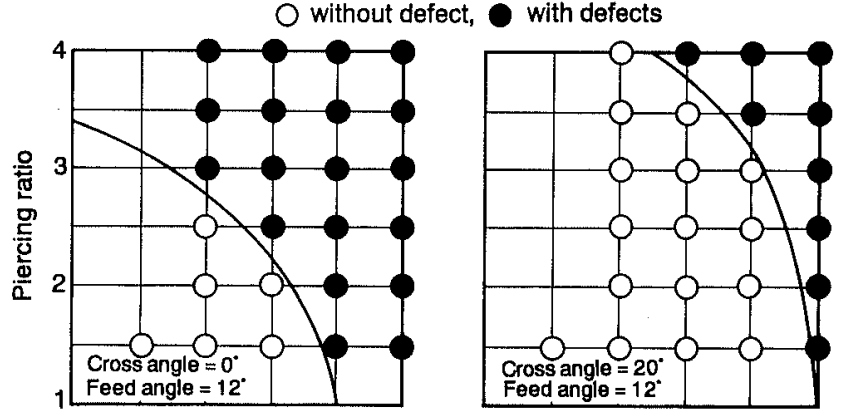

(a) Influences of heating temperature, piercing ratio and cross angle.
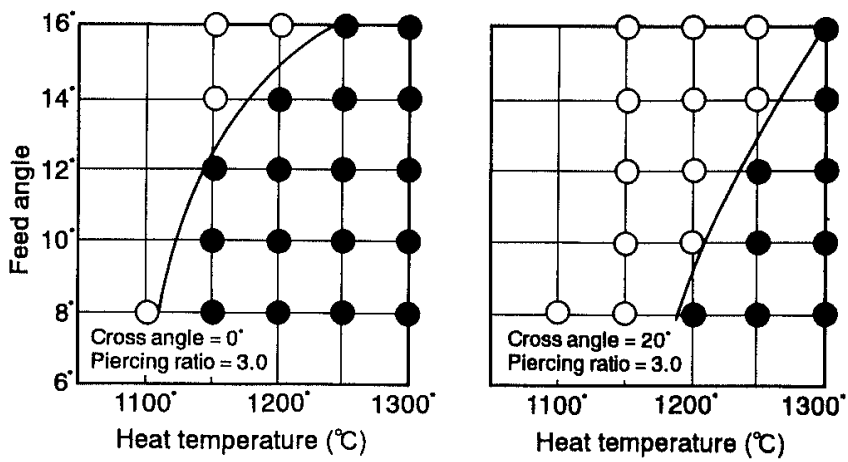

(b) Influences of heating temperature, feed and cross angle.

Fig. 10. Influences of the heating temperature and piercing ratio on the inside bore and lamination defects in high alloy steel. $(25 \mathrm{Cr}-50 \mathrm{Ni}-6 \mathrm{Mo})$ 
results are summarized as follows.

(1) Irrespective of the type of high alloy steel, the larger the feed and cross angle are, and the smaller the piercing ratio is, the less are the inside bore and lamination defects.

(2) In the case of $25 \mathrm{Cr}-35 \mathrm{Ni}-3 \mathrm{Mo}$ and $30 \mathrm{Cr}-40 \mathrm{Ni}-$ $3 \mathrm{Mo}$ steel, no appreciable difference can be observed at the cross angles ranging from $10^{\circ}$ to $15^{\circ}$. When the cross angle is larger than $20^{\circ}$, a good inside bore quality free from inside bore and lamination defects can be obtained.

(3) In the case of $25 \mathrm{Cr}-50 \mathrm{Ni}-6 \mathrm{Mo}$, the influence of the cross angle is very clear: when the cross angle is set at $10^{\circ}$, the lowest feed angle is $16^{\circ}$ to prevent the inside bore and lamination defects. On the other hand, when the cross angle is larger than $15^{\circ}$, the corresponding feed angle is decreased to $14^{\circ}$.

(4) In the case of $20 \mathrm{Cr}-50 \mathrm{Ni}-9 \mathrm{Mo}$, the influence of the cross angle is far more remarkable: piercing at a cross angle of $10^{\circ}$ has some difficulty, but when the cross angle is $15^{\circ}$, as well as $20^{\circ}$, a good inside bore quality can be stably obtained at a feed angle of $16^{\circ}$ and more.

(5) The influences of the feed and cross angle, piercing ratio and heating temperature on the inside bore and lamination defects in high alloy steel are similar to those in stainless steel. The mechanisms of the initiation and propagation of these defects are same.

\section{Influences of the Feed and Cross Angle on the Inside Bore Defects in Free Cutting Steel}

\subsection{Experimental Procedure}

The hot workability of $\mathrm{Pb}-\mathrm{S}$ type free cutting steel, which is carbon-steel based is as poor as or inferior to that of stainless steel or high alloy steel.

Piercing experiments were carried out with $70 \phi$ forged billets of $0.2 \mathrm{~Pb}-0.2 \mathrm{~S}$ free cutting steel, by changing the feed and cross angle, piercing ratio, heating temperature and draft ratio at the tip of the plug. The influences of the feed and cross angle, piercing ratio, draft ratio at the tip of the plug and heating temperature on the inside bore defects in $\mathrm{S}-\mathrm{Pb}$ free cutting steel were examined in detail. The piercing ratio was set within the range from 2.0 to 3.5 , the draft ratio from 6 to $9 \%$, and the heating temperature from $1100^{\circ}$ to $1300^{\circ} \mathrm{C}$.

\subsection{Experimental Results and Discussion}

The influences of the feed and cross angle, piercing ratio and draft ratio on the inside bore defects in $0.2 \mathrm{~Pb}-$ $0.2 \mathrm{~S}$ free cutting steel are shown in Figs. 11 and 12, and those of the heating temperature and piercing ratio in Fig. 13. The results are summarized as follows.

(1) The influences of the feed and cross angle and piercing ratio on the inside bore defects in $\mathrm{Pb}-\mathrm{S}$ free cutting steel are similar to those in stainless steel. The larger the feed and cross angle are, and the smaller the piercing ratio is, the less are the inside bore defects.

(2) If the draft ratio is too large, inside bore defects tend to occur easily. The hot workability of the $0.2 \mathrm{~Pb}-$ $0.2 \mathrm{~S}$ free cutting steel depends on the draft ratio at the tip of the plug. Therefore, the draft ratio should be on the order of $7 \%$.
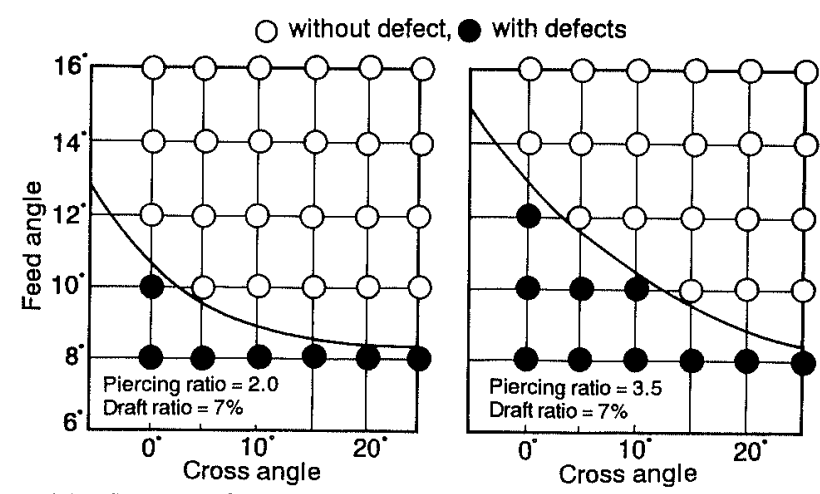

(a) Influences of piercing ratio, feed and cross angle.
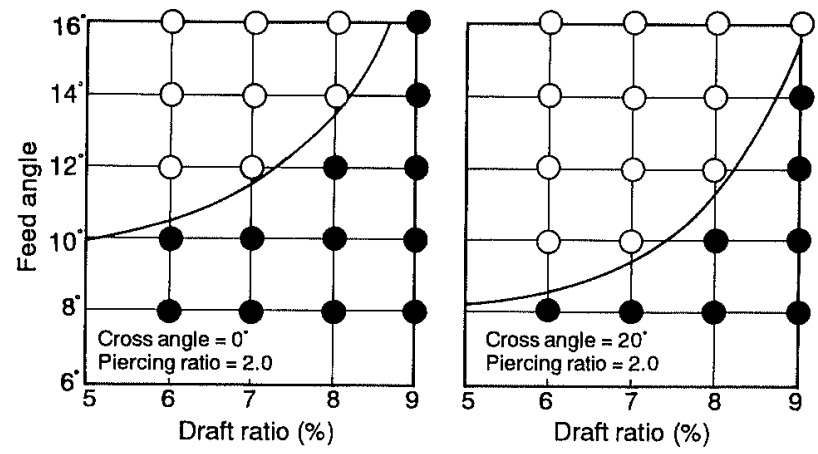

(b) Influences of draft ratio, feed and cross angle.

Fig. 11. Influences of the feed and cross angle, piercing ratio, heating temperature and draft ratio on the inside bore defects in free cutting steel. $(0.2 \mathrm{~Pb}-0.2 \mathrm{~S})$

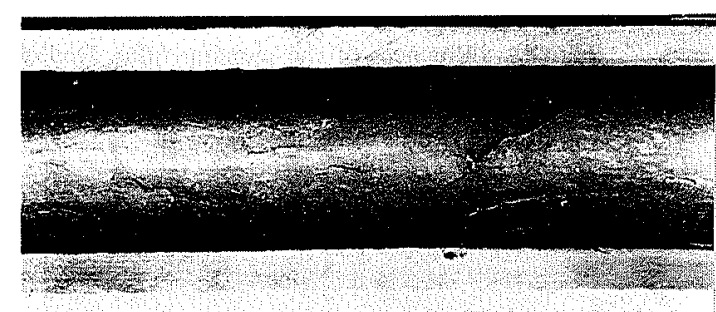

(a) Cross angle $=0^{\circ}$, Feed angle $=8^{\circ}$

Piercing ratio $=3.0$, Heat temperature $=1200^{\circ} \mathrm{C}$

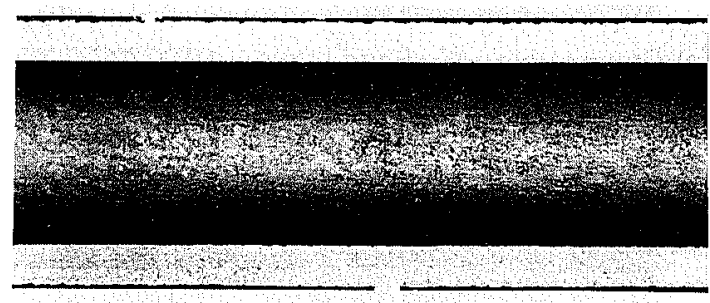

(b) Cross angle $=20^{\circ}$, Feed angle $=14^{\circ}$

Piercing ratio $=3.0$, Heat temperature $=1200^{\circ} \mathrm{C}$

Fig. 12. Influences of the feed and cross angle on the inside bore defects in free cutting steel. $(0.2 \mathrm{~Pb}-0.2 \mathrm{~S})$

(3) The influence of the heating temperature is slightly different from that in stainless steel. The higher the heating temperature is, the less are the inside bore defects. 


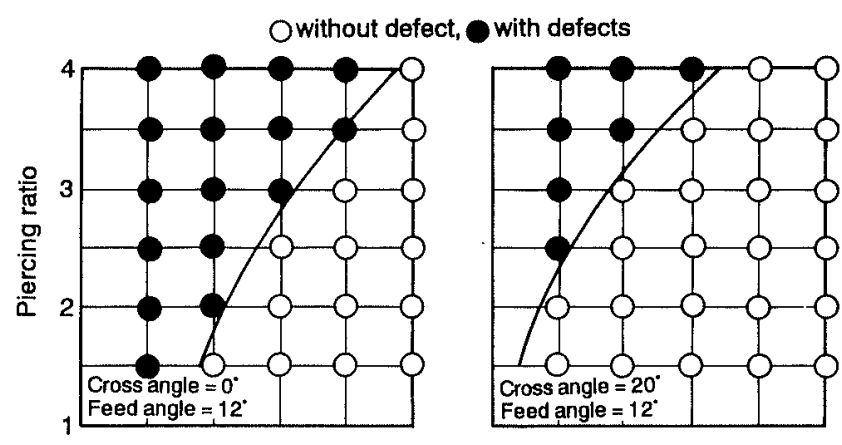

(a) Influences of heating temperature, piercing ratio and cross angle.
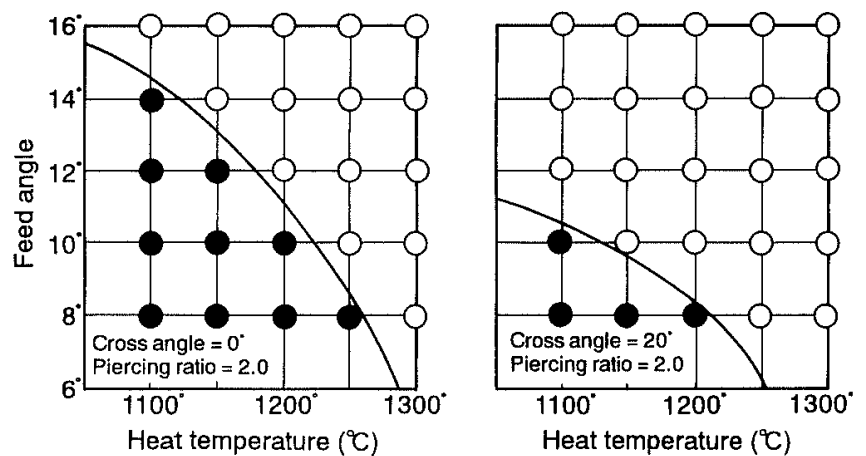

(b) Influences of heating temperature, feed and cross angle.

Fig. 13. Influences of the heating temperature and piercing ratio on the inside bore defects in free cutting steel. $(0.2 \mathrm{~Pb}-0.2 \mathrm{~S})$

\section{Influences of the Feed and Cross Angle on the Inside Bore Defects in Non-ferrous Metals}

\subsection{Experimental Procedure}

The development of the cone-type piercing process has made it possible to pierce these billets with poor hot workability such as stainless, high alloy and free cutting steel, with no inside bore and lamination defect. In order to examine the applicability of this technology to the piercing of other materials, piercing experiments were carried out with non-ferrous metals under the same piercing setup. The forged billets of typical non-ferrous metals, such as pure titanium (Ti), titanium alloy (Ti-6Al-4V), zircalloy $(98.3 \mathrm{Zr}-1.5 \mathrm{Sn})$, pure nickel (Ni), Kovar (26Ni-16Co-Fe), Monel (65Ni-30Cu), Invar (36Ni-Fe), Elinvar $(42 \mathrm{Ni}-5 \mathrm{Cr}-2 \mathrm{Ti}-\mathrm{Fe})$ and shape memory alloy (55Ni-45Ti) were used as test specimens in the piercing experiments. The inside bore quality, particularly the inside bore and laminations defects of the pierced specimens were examined. The piercing ratio was set within the range from 2.0 to 2.5 , and the expansion ratio from 1.03 to 1.10 .

\subsection{Experimental Results and Discussion}

The results are summarized as follows.

(1) With reference to pure titanium (Ti), titanium alloy $(\mathrm{Ti}-6 \mathrm{Al}-4 \mathrm{~V})$, zircalloy $(98.3 \mathrm{Zr}-1.5 \mathrm{Sn})$ and pure nickel (Ni), the experiments show that piercing under the conditions of feed angle $\beta=12^{\circ}$ and cross angle $\gamma=10^{\circ}$ causes no inside bore defect and provides a satisfactory inside bore quality.

(2) With reference to Kovar $(26 \mathrm{Ni}-16 \mathrm{Co}-\mathrm{Fe})$, Monel (65Ni-30Cu), Invar (36Ni-Fe), Elinvar (42Ni-
$5 \mathrm{Cr}-2 \mathrm{Ti}-\mathrm{Fe}$ ) and shape memory alloy (55Ni-45Ti), the experiments show that piercing under the conditions of feed angle $\beta=12^{\circ}$ and cross angle $\gamma=20^{\circ}$ causes no inside bore defect and provides satisfactory inside bore quality.

(3) After all, this piercing setup can be also employed for defect-free piercing for non-ferrous metals.

\section{Conclusions}

The principal conclusions can be summarized as follows.

(1) When a continuously cast round billet, even of carbon steel, is pierced, the center porosities of the billet tend to develop into the micro bore defects under the influence of the shear stress field. The influences of the feed and cross angle on the number of the micro bore defects in a shell pierced from the continuously cast round billet are very apparent. The larger the feed and cross angle are, the more remarkable is the decrease in the number of the micro bore defects. The effect of the electromagnetic stirring is also very apparent. The application of the electromagnetic stirring in combination with the cone-type piercing process results in a sharp decrease in the number of the micro bore defects to almost none.

(2) The hot workability of stainless steel is far inferior to that of carbon steel. When the material is pierced, voids may occur from any inclusions and/or segregations in front of the plug. Then, the material becomes brittle, which leads to the initiation of inside bore defects. Furthermore, during piercing operation, cracks will propagate in the redundant shear stress field and they develop into the conspicuous inside bore defects. The influences of the feed and cross angle on the inside bore defects in stainless steel are very clear. The larger the feed and cross angle are, the less are the inside bore defects. The hot workability of stainless steel, in the form of a continuously cast round billet, is so poor that lamination defects may occur in a central portion of the wall. In this conjunction, the influences of the feed and cross angle on the lamination defects are very apparent.

(3) The hot workability of high alloy steel is still poorer than that of stainless steel. When it is pierced, the material tends to suffer not only noticeable inside bore defects, but also lamination defects occurring in a central portion of the wall. The influences of the feed and cross angle on the inside bore and lamination defects in high-alloy steel are very clear. By employing the cone-type piercing process, the high alloy steel can be satisfactorily pierced free from any inside bore and lamination defects. In the case of stainless or high alloy steel, a suitable heating temperature should be selected considering the heat generation due to piercing operation.

(4) The hot workability of $\mathrm{Pb}-\mathrm{S}$ free cutting steel is as poor as or worse than those of stainless and high alloy steels. The influences of the feed and cross angle on the inside bore defects in $\mathrm{Pb}-\mathrm{S}$ free cutting steel are also very clear. The cone-type piercing process under the condition of a high feed and cross angle provides satisfactory piercing without causing inside bore defects. 
(5) Any materials with poor workability, such as stainless, high alloy and $\mathrm{S}-\mathrm{Pb}$ free cutting steel, can be pierced under the condition of a high feed and cross angle, resulting in the satisfactory bore quality free from inside bore and lamination defects. This identical piercing setup can be employed for defect-free piercing for non-ferrous metals, such as titanium, titanium alloy, zirconium alloy, nickel and nickel alloy. There is no quality problem.

\section{REFERENCES}

1) T. Tanaka, K. Hemmi, C. Hayashi, M. Utakoji and K. Nishikawa: The 31st Okochi Memorial Prize, (1985), 34

2) C. Hayashi, M. Utakoji and K. Yoshioka: Proc. of the 3rd ICSR, Tokyo, (1985), 174.

3) C. Hayashi; Proc. of ICMSR, Beijing, (1989), 57.

4) C. Hayashi and T. Yamakawa; ISIJ Int., 37 (1997), 146.

5) T. Okamoto, C. Hayashi and M. Nishiguchi: JPN Patent 808493 , US Patent 3719066, UK Patent 1320035.

6) C. Hayashi: JPN Patent 1608310, US Patent 4470282, UK Patent 2096505.

7) C. Hayashi: JPN Patent 1812697, US Patent 4827750, UK Patent 2202778. 